\title{
RECURSOS MIDIÁTICOS E GEOGRAFIA ESCOLAR: propostas metodológicas em busca da renovação no ensino
}

\author{
MEDIA RESOURCES AND SCHOLASTIC GEOGRAPHY: \\ methodological proposals on search of renewal of the education
}

\author{
Suellen Silva Pereira \\ Doutora em Recursos Naturais \\ UEPB \\ suellenssp@hotmail.com \\ Telma Lúcia Bezerra Alves \\ Doutora em Recursos Naturais \\ UEPB \\ telmaluciax@hotmail.com \\ Laíse do Nascimento Cabral \\ Mestranda em Recursos Naturais \\ UEPB \\ laisedonascimentocabral@hotmail.com
}

\begin{abstract}
Resumo:
A necessidade de renovação no processo de ensino-aprendizagem da Geografia Escolar, de modo que esta venha a motivar a participação do aluno no processo de construção do conhecimento, é tema recorrente entre estudiosos da área. Diante das grandes transformações ocorridas no contexto social na atualidade, o papel do educador mudou completamente. É preciso mudar também a perspectiva didático-pedagógica diante deste novo cenário. Neste contexto, a introdução de recursos midiáticos (vídeo, música, documentários, jornais, dentre outros) torna-se imprescindível para que ocorra uma mudança na prática de ensino. Desse modo, o presente artigo tem por objetivo discorrer sobre a utilização de alguns recursos midiáticos em sala de aula, bem como analisar a aplicabilidade destas novas metodologias nas aulas de Geografia, através de propostas metodológicas, de modo a nortear o professor no planejamento de suas aulas. Como estratégia, procedeu-se uma revisão da literatura sobre o ensino de Geografia e a necessidades de novas abordagens didático-pedagógicas em sala de aula. Observou-se, que a introdução de mídias em sala de aula possibilita uma maior interação dos alunos, favorecendo maior contextualização e significação dos conceitos apreendidos.
\end{abstract}

Palavras-chave: Geografia Escolar; Prática Pedagógica; Recursos Didáticos; Mídia; Renovação.

\section{Abstract:}


The necessity of the renovation on teaching-apprenticeship process of the scholastic Geography, in a way that come the motivate the pupil' participation on process to knowledge of construction; is a recurrent theme between scholars of the scope. Before the large transformations in the social context in present, the craft of educator changed utterly. Have to change also the pedagogical-didactic perspective on this new scenery. In this context, the insertion of media resources (video, music, documentaries, and newspapers, others among) becomes indispensable for occur a change in the education practice. This article has by objective descant about the utilization of some media resources on the classroom, and analyze the applicability of these new methodologies at the Geography lessons, by methodological proposals, for guide the teacher on planning their lessons. As strategy, was done a revision of the bibliography about the teaching of the Geography and the need of the new pedagogical-didactic approaches on the classroom. Noted, that introduction of media on the classroom possibility a larger interaction, favoring a larger contextualization and signification of the seized concepts.

Keywords: Scholastic Geography; Pedagogical Practice; Didactic Resources; Media; Renovation.

\section{INTRODUÇÃO}

Diante de um cenário de crise no sistema educacional brasileiro, a busca por renovação no processo de ensino e aprendizagem, vem se mostrando uma constante. Neste contexto, a introdução de recursos midiáticos (vídeo, música, documentários, jornais, dentre outros) vem se apresentando como um instrumento imprescindível para que ocorra uma mudança na prática de ensino, despertando no professor sua importância como agente formador de opinião e não apenas como um mero reprodutor de conteúdos.

$\mathrm{Na}$ tentativa de buscar a inovação em sala de aula, principalmente no que se refere às mídias, é comum o professor desenvolver em sala de aula uma prática "tradicional", ou seja, aquela consolidada com sua experiência profissional - transmitindo o conteúdo para os alunos - e, num outro momento, utilizando os recursos tecnológicos como um apêndice da aula. São procedimentos que revelam intenções e tentativas de integração de mídias na prática pedagógica. Revelam, também, um processo de transição entre a prática tradicional e as novas possibilidades de reconstruções. No entanto, neste processo de transição, pode ocorrer muito mais uma justaposição (ação ou efeito de justapor $=$ pôr junto, aproximar) das mídias na prática pedagógica do que a integração (PRADO, 2009). 
Em se tratando do Ensino de Geografia, faz-se oportuno ressaltar o estigma que a disciplina em questão vem sofrendo ao longo dos anos, diante de uma desvalorização desta desde o período ditatorial, permanecendo seus resquícios até os dias de hoje. Fato este que faz com que a citada ciência seja tachada de disciplina "decoreba", "chata" e "mnemônica" pelos alunos, haja vista que os conteúdos, conceitos e categorias geográficas, são, por vezes, apresentados aos alunos descontextualizados do seu espaço vivido, o que suscita o descredito e desinteresse por parte destes. Fato este que pode ser percebido em pesquisa realizada por Cavalcanti (2010, p.129), na qual verificada a seguinte situação:

Os alunos da pesquisa, no geral, afirmam não gostar da Geografia estudada na escola. Pelos dados, $32 \%$ dos alunos declararam não gostar de Geografia e $10 \%$ declararam gostar "mais ou menos". Além disso, um outro dado relevante é o índice de rejeição pela matéria: $23 \%$ apontaram a Geografia como uma das três matérias que menos gostam.

Tamanho desinteresse pelas aulas de Geografia pode estar associado a diversos fatores, podendo ressaltar, como uma das questões fundamentais para tal problemática, conforme apontado pelos autores que discutem e debatem o ensino de Geografia (Resende, 1986); (Vesentini, 1994); (Oliveira, 1994); (Callai, 2002); (Kaercher, 2002), (Katuta, 2004), a dificuldade dos professores em estabelecer uma relação entre os conteúdos estudados e o cotidiano dos alunos, a realidade concretamente vivida e experenciada pelos educandos. De acordo com Kaercher (2002, p. 223):

[...] o ensino de Geografia continua desacreditado. Os alunos, no geral, não têm mais paciência para nos ouvir. Devemos não apenas nos renovar, mas ir além, romper a visão cristalizada e monótona da Geografia como ciência que descreve a natureza e/ou dá informações gerais sobre uma série de assuntos e lugares. Devemos fazer com que o aluno perceba qual a importância do espaço na constituição de sua individualidade e da(s) sociedade(s) de que ele faz parte (escola, família, cidade, país, etc.).

Desse modo, o presente artigo tem por objetivos: discorrer sobre a utilização de alguns recursos midiáticos em sala de aula, bem como analisar a aplicabilidade destas novas metodologias nas aulas de Geografia, de modo a nortear o professor no planejamento de suas aulas, como forma de superar e/ou ultrapassara a dependência quadro e giz, perpassando esta renovação por propostas metodológicas que incentivem, facilitem e promovam o saber geográfico de modo a desmistificar o caráter mnemônico que envolve a Geografia. 
Como estratégia, procedeu-se uma revisão da literatura sobre o ensino de Geografia e a necessidades de novas abordagens didático-pedagógicas em sala de aula. Dessa forma, o presente trabalho se caracteriza por ser um Ensaio Teórico, cujo método foi o analítico-descritivo, haja vista que este pretende analisar a necessidade de renovação da Geografia Escolar, como forma de buscar uma (re)significação para o ensino de Geografia, ao tempo que descreve novas possibilidades didático-pedagógicas tendo como aporte os recursos midiáticos, além de apresentar proposta metodológicas para utilização das novas tecnologias em sala de aula.

\section{A PRÁTICA PEDAGÓGICA EM GEOGRAFIA}

Mesmo sendo a Geografia essencial para a compreensão das relações espaciais, entre o homem e o espaço geográfico, como também para a formação de uma base crítica, o que possibilita a análise de fatores sociais, políticos e econômicos, esta ciência não é observada dessa forma, principalmente em se tratando da Geografia Física, o que a fez ficar conhecida como uma disciplina "chata" de ser estudada e desenvolvida, ao ponto de ser taxada pelos alunos como uma disciplina de "pura decoreba".

Com a modernização nos meios de comunicação e a consequente expansão da tecnologia, se faz necessário uma modificação no método de ensino-aprendizagem, para que este possa acompanhar o processo evolutivo, adequando-se as novas exigências da sociedade.

Nesse contexto, é de fundamental importância à renovação do ensino de Geografia, baseada na inovação de materiais didático-pedagógicos que possibilitem aos alunos um novo olhar para tal disciplina, despertando o interesse destes pelas aulas. De acordo com Pinheiro et. al. (2004, p. 104):

Para romper esse estigma, alguns professores buscam várias maneiras de renovar o ensino. Nas transformações por que passa a escola, com vista à reformulação dos métodos educacionais, os materiais didáticos são importantes no trabalho do professor. Eles se constituem em instrumentos que possibilitam planejar boas situações didáticas, buscando promover a ampliação dos conhecimentos dos alunos, permitindo-lhes desenvolver conceitos, problematizar questões e articular conteúdos. Para isso, o professor deverá criar situações concretas de aprendizagem. 
A constatação evidenciada no fragmento de texto acima exposto pode ser corroborada pelos PCN's (BRASIL, 2001, p. 153) quando estes, ao discorrerem sobre as práticas de ensino da Geografia, afirmam que:

\begin{abstract}
O ensino de Geografia, de forma geral, é realizado por meio de aulas expositivas ou da leitura dos textos do livro didático. Entretanto, é possível trabalhar com esse campo do conhecimento de forma mais dinâmica e instigante para os alunos, mediante situações que problematizem os diferentes espaços geográficos materializados em paisagens, lugares e territórios; que disparem relações entre o presente e o passado, o específico e o geral, as ações individuais e as coletivas; e promovam o domínio de procedimentos que permitam aos alunos "ler" a paisagem local e outras paisagens presentes em outros tempos e espaços.
\end{abstract}

É importante ressaltar que os equipamentos que permitem essas práticas não podem ser priorizados pela metodologia de aprendizagem, apenas pelo seu simples domínio e uso. São as formas de usar suas possibilidades de comunicação e de informação que se constituem alternativas didáticas. Assim, projetar um filme, acessar a internet, capturar um texto, assistir a um programa televisivo, escrever um texto no computador são ações que se tornam educativas pela intencionalidade pedagógica do ensinar e do aprender, não porque são práticas do nosso tempo (MELO et. al., 2009).

\title{
RECURSOS MIDIÁTICOS: novas possibilidades didático-pedagógicas em sala de
} aula

No mundo atual, é possível identificar ampla diversidade de linguagens em um contexto marcado por infinidade de informações. A sociedade é cada vez mais uma sociedade da informação, fruto da revolução tecnológica responsável pela rapidez cada vez maior dos meios de comunicação. Entretanto, pode-se dizer que tal situação não tem garantido a inserção crítica dos indivíduos na sociedade, uma vez que, via de regra, as informações são descontextualizadas e fragmentadas, além de inúmeras e distintas, o que dificulta o estabelecimento de relações entre elas e não permite considerá-las na categoria do conhecimento (PONTUSCHKA et. al., 2009, p. 261).

Neste contexto, a escola cumpre um importante papel ao apropriar-se das várias modalidades de linguagens como instrumentos de comunicação, devendo, portanto, promover o processo de análise e interpretação das informações, ao tempo que possibilita ao aluno o contato mais direto e estreito com as novas tecnologias no processo de ensino-aprendizagem. 
De acordo com Pontuschka et. al. (2009), a escola deve ser considerada o lugar de reflexão acerca da realidade, seja ela local, regional, nacional ou mundial, fornecendo instrumental capaz de permitir ao aluno a construção de uma visão organizada e articulada do mundo, cabendo ao professor o papel de mediador entre o aluno e a informação recebida, promovendo o "pensar sobre" e desenvolvendo a capacidade do aluno de contextualizar, estabelecer relações e conferir significados as informações.

Assim sendo, diante de um meio técnico-científico-informacional o qual estamos inseridos, como colocado por Milton Santos, faz-se extremamente necessário que o professor saiba lidar com as diferentes linguagens utilizadas para a análise geográfica e tenha domínio das novas tecnologias para seu posterior uso com os alunos. Callai acrescenta que: "filmes, vídeos, clips musicais, músicas, artigos de revistas, jornais, podem nos levar aos conteúdos da disciplina, exigindo-se do professor apenas que tenha os referenciais teóricos e metodológicos da sua ciência" (2003, p.88).

Dentre as diversas possibilidades midiáticas a disposição dos professores atualmente, o presente artigo apresenta alguns desses recursos, ao tempo que propõe alternativas metodológicas para se trabalhar com mídias em sala de aula. Outrossim, ressalta-se que as propostas a serem apresentadas podem vir a ser aplicadas aos alunos do Ensino Fundamental II, assim como do Ensino Médio, cabendo apenas uma adequação dos objetivos, bem como dos questionamento propostos, como forma de ajustar o conteúdo à idade/série dos alunos. Assim sendo, para a presente reflexão, recorreu-se a 03 (três) recursos midiáticos, sendo estes a música, o jornal impresso e filmes/documentários, conforme explicitado a seguir:

\section{Trabalhando com a Música em sala de aula}

Dentre as novas formas de ensinar e aprender o conteúdo geográfico, destaca-se a utilização de letras de músicas, podendo estas serem utilizadas como complemento metodológico, tendo em vista a variedade de ritmos e assuntos abordados nas letras, conforme colocado por Vieira e Sá (2007, p. 107):

\footnotetext{
A música pode ser um complemento auxiliar das atividades desenvolvidas para a interação com alunos nos trabalhos de ensinar e aprender Geografia. O professor não precisa conhecer nem compartilhar as preferências dos gêneros musicais de seus alunos, mas pode propor que eles façam um levantamento das músicas que tratem do tema em estudo. Por exemplo, "Três Raças", de Clara Nunes, pode ser introduzida no 
estudo da população. A receptividade é quase sempre muito boa e promove a concentração.

Diante do exposto, cabe ao professor desenvolver reflexões sobre o desenvolvimento da sua prática pedagógica, assim como ressalta Paulo Freire (2009), “a reflexão crítica sobre a prática se torna uma exigência da relação Teoria/Prática sem a qual a teoria pode ir virando blábláblá e a prática, ativismo" (p. 22).

De acordo com Oliveira et. al. (2005, p. 74), aliar essa facilidade de assimilação encontrada nos mais diversos gêneros musicais às propostas metodológicas e curriculares da Geografia pode gerar bons resultados. Dificilmente se encontrará algo mais atrativo, entre crianças e jovens, do que o compartilhar suas preferências, sua reprovação ou aprovação às obras musicais, com seus colegas e professores.

A variedade de conteúdos e gêneros musicais encontrados pode ser um fator facilitar para a sua utilização, como demonstrado por Costa (2002 apud PINHEIRO et. al., 2004, p. 104) ao abordar que:

\begin{abstract}
Uma das vantagens de se utilizar a música na Geografia se afirma na pluralidade de assuntos abordados por esta ciência. Violência, guerras, conflitos raciais, fome, falta de infraestrutura nas cidades, belezas naturais, como também degradação ao meio ambiente, fazem parte dos temas abordados por muitos compositores [...].
\end{abstract}

Para Pinheiro et. al. (2004), apesar da música não ilustrar visualmente o conteúdo a ser explorado, ela se constitui em um veículo de expressão capaz de aproximar mais o aluno do tema proposto a ser estudado. Dificilmente se encontra uma pessoa que não goste de música. Aproveitando a facilidade com que a música é assimilada, principalmente pelos jovens, pode-se usar desse recurso fazendo uma conexão com o conteúdo disciplinar de forma prazerosa, de modo que todos consigam aprender. Ela sempre está presente na vida das pessoas. Desde as primeiras manifestações culturais das civilizações, sempre foi um meio de expressão do modo de vida de uma sociedade. Por isso:

A educação da Geografia através da música proporciona a vivência da linguagem musical como um dos meios de representação do saber construído pela interação intelectual e afetiva do homem com o meio ambiente, pois a interação natureza-sociedade faz parte do cotidiano de todos os seres humanos do planeta (COSTA apud PINHEIRO, 2004, p. $105)$. 
Com isso, cabe ao professor fazer uma escolha criteriosa das músicas a serem trabalhadas com seus alunos em sala de aula, analisando a sua adequação com a temática em estudo, e o que esta tem a oferecer para um maior enriquecimento das aulas a serem ministradas, extraindo do alunado sua posição crítica diante do estudo, buscando sempre uma correlação com a temática proposta e a realidade de vida de cada aluno, uma vez que, cada indivíduo possui um contexto de vida único, sendo este passível de abordagem em sala de aula.

\section{- Proposta metodológica: o semiárido nordestino nas músicas de Luiz Gonzaga}

O semiárido brasileiro foi retratado com bastante fidedignidade nas canções de Luiz Gonzaga, o qual deixou um rico acervo musical, podendo este ser explorado em sala de aula de modo a trabalhar os conteúdos geográficos, relacionando-os com os elementos característicos desta região, fazendo-se necessário que as escolas inseridas nessas localidades passem a trabalhar com uma educação contextualizada com a realidade dos educandos, podendo uma dessas iniciativas perpassar por um reconhecimento e, consequente, valorização dos elementos que compõem tais localidades, quer sejam o clima, a vegetação, o relevo, a hidrografia, a cultura, dentre outros. Assim sendo, esta proposta poderá ser utilizada como complementação metodológica, aos conteúdos relacionados à Geografia do Nordeste.

Tomando por base as colocações de Pinheiro et. al. (2004), ressalta-se que ao se trabalhar com música em sala de aula, faz-se necessário, primeiramente, uma interpretação da letra, de modo a identificar os elementos que estão sendo representados; correlacionar a música com os conteúdos que serão trabalhados; elencar os termos desconhecidos pelos alunos contextualizando-os para a compreensão da letra e, por conseguinte, o aprendizado. Abaixo segue a letra, juntamente com os objetivos propostos.

\section{Música: Baião da Garoa (Luiz Gonzaga e Hervé Cordovil)}

Na terra seca/ Quando a safra não é boa/ Sabiá não entoa/ Não dá milho e feijão/ Na Paraíba, Ceará nas Alagoas/ Retirantes que passam/ Vão cantando seu rojão/ Tra, lá, lá, 
lá, lá, lá, lá - (Bis)/ Meu São Pedro me ajude/ Mande chuva, chuva boa/ Chuvisquinho, chuvisqueiro/ Nem que seja uma garoa/ Uma vez choveu na terra seca/ Sabiá então cantou/ Houve lá tanta da fartura/ Que o retirante voltou/ Tava lá eu na pisada $(2 \mathrm{x}) / \mathrm{Tum}$, tum, Tum/ Oi! Graças a Deus/ Choveu, garoou.

O objetivo principal desta atividade é estudar as condições climáticas da Região Nordeste e sua interferência na agricultura, dessa forma, pretende-se:

1. Identificar os elementos climáticos presente na letra da música;

2. Relacionar a interferência climática na atividade agrícola;

3. Elencar elementos que sejam comuns no cotidiano dos alunos, de modo a aproximar o conteúdo do seu espaço vivido, com vista à construção de uma Geografia mais humanista;

4. Destacar, utilizando o mapa climático e de vegetação da Região Nordeste, qual a interferência do clima na configuração da paisagem local;

5. Pesquisar sobre as principais culturas desenvolvidas na região onde moram e a importância desta atividade para a vida dos agricultores; bem como de suas famílias;

6. Discutir sobre a importância da água para a atividade agrícola; bem como investigar alternativas de convivência com a escassez típica da região semiárida, compreendendo a seca como um fenômeno natural, culminando com a elaboração de uma redação abordando a temática discutida.

\section{O Jornal impresso nas aulas de Geografia}

De acordo com Farias (2004), o jornal se caracteriza por ser uma fonte primária de informação, tornando-se, assim, um instrumento importante para o leitor se situar e se inserir na vida social e profissional. Como apresenta um conjunto dos mais variados conteúdos, preenche plenamente seu papel de objeto de comunicação. Mas não só, pois como os pontos de vista costumam ser diferentes, e mesmo conflitantes, ele leva o aluno a conhecer diferentes posturas ideológicas frente a um fato, a tomar posições fundamentadas e a aprender a respeitar os diferentes pontos de vista, necessários ao pluralismo numa sociedade democrática.

Ainda de acordo com o autor supracitado, a leitura do jornal se for bem conduzida, ela prepara leitores experientes e críticos para desempenhar bem seu papel 
na sociedade. Sendo este recurso utilizado em sala de aula, o mesmo auxiliaria no processo de ensino-aprendizagem do aluno, visto que a leitura crítica do jornal aumenta sua cultura e desenvolve suas capacidades intelectuais.

Diante de uma aparente rejeição, por parte dos alunos, para o exercício da leitura, haja vista que os textos por vezes apresentam uma linguagem rebuscada, distante da realidade dos alunos, o que dificulta o entendimento e aprendizado, poderia o jornal ser um possível instrumento para o incentivo à leitura. Podendo esta assertiva ser complementada por Augusto (2004, s/p), quando o autor discorre que:

Em tempos de interatividade via telefone celular e internet, fazer com que as
crianças se interessem pela leitura de jornais não é tarefa das mais fáceis, mas
certamente é fundamental para formar leitores habituais e cidadãos bem-
informados. Trazendo textos com características distintas, fotografia e
recursos gráficos, os jornais são uma fonte respeitada para pesquisa e para a
obtenção de informação sobre o mundo atual. Além disso, eles se
modernizaram e passaram por reestruturações gráficas e editoriais para
proporcionar leitura mais agradável de seu conteúdo.

Nas palavras de Pavini (2002, p. 25): “A imprensa escrita, diária e local, oferece diversas possibilidades à criança e ao adolescente de exercitarem variadas formas de aprendizagem tendo por base temas da atualidade [...]”. Aliás, a utilização do jornal na sala de aula aparece desde o século XIX como uma contraposição ao conteúdo oferecido pelos livros didáticos ou clássicos literários. Na Espanha, a leitura de jornais já era vista no final do século XIX e início do século XX como alternativa à obrigatoriedade de se ler Miguel de Cervantes (GAIA, 2002).

Diante do exposto, a utilização de jornal em sala de aula é bastante pertinente, principalmente quando se trata da disciplina de Geografia, uma vez que este material ao ser introduzido, como um aporte teórico-metodológico nas aulas, pode vir a aproximar o conteúdo disciplinar da vida cotidiana do aluno, devido à variedade de assuntos abordados, tornando este mais significativo, além de tornar as aulas mais interessantes.

Ressaltando a informação acima exposta, Santos e Callai (2009) ressaltam que esta prática visa, sobretudo, ampliar os conhecimentos dos alunos acerca de determinados temas geográficos, bastante presente nos jornais, além de associar a teoria e a prática. Kaercher (2003) em seu artigo "Geografizando o Jornal e outros cotidianos: práticas em Geografia para além do livro didático", coloca a importância de 
trabalharmos o jornal em sala de aula, no intuito de mostrar a cotidianidade do espaço geográfico em nossa vida (SANTOS e CALLAI, 2009).

Nesse contexto, Castellar (2010) salienta que ao dispormos de artigos de jornais nas aulas, o impacto que essa atividade causa para a aprendizagem é muito estimulante, pois pode provocar uma série de perguntas por parte dos alunos. No entanto a autora coloca a necessidade do professor organizar um conjunto de atividades, como o uso do jornal, por exemplo, onde convêm conhecer as notícias e articulá-las, pois nem sempre um artigo possui vínculo direto com o conteúdo estudado.

Além dos fatores acima elencados, soma-se a este o fato de o jornal ser um instrumento de aprendizado de fácil acesso, o que viabiliza a sua utilização em sala de aula, sendo esta constatação ressaltada por Guimarães (2003, p.30) quando afirma que:

\begin{abstract}
A utilização de jornais e revistas nas aulas de Geografia é bastante comum por parte dos professores. [...] Isso ocorre porque, além desse tipo de material ser valorizado pelos docentes, tanto o acesso a ele como a maneira de trabalhar com ele em sala de aula são bem mais simples do que em relação à TV e vídeo. Para trabalhar com jornais e revistas os professores não precisam enfrentar as dificuldades de gravar o programa ou consegui-lo em locadoras de vídeo, em outras instituições ou ainda com terceiros. Além disso, não precisam passar pela desgastante tarefa de reservar a sala de projeção ou, como em muitas escolas, levar o equipamento para a sala de aula.
\end{abstract}

Para Alves e Cardoso (2008), ao invés de obrigar os alunos a lerem e tentarem interpretar apenas textos didáticos, o professor pode fazer uma associação do texto escolar conteudista com notícias publicadas no jornal impresso. Os docentes, ao levarem as notícias para a sala de aula, devem auxiliar o aluno a interpretá-las, desvencilhando-se de interesses externos, procurando as diversas leituras possíveis do mesmo fato.

Além disso, tomando por base as colocações de Kozel (2006), os meios de comunicação, como o jornal, proporcionam a aproximação de espaços distintos, estabelecendo ligações entre as diferentes, mas indissociáveis, escalas espaciais - ou escalas de análise geográfica (do local ao global), o que raramente é considerado nas práticas pedagógicas em Geografia. Tais meios apresentam os principais acontecimentos, sejam estes locais, nacionais ou globais, de modo rápido e atualizado.

- Proposta metodológica: discutindo a violência urbana nas aulas de Geografia através do jornal impresso

Geo UERJ - Ano 15, nº. 24, v. 2, $2^{\circ}$ semestre de 2013

ISSN: 1415-7543 E-ISSN: 1981-9021

http://www.e-publicacoes.uerj.br/index.php/geouerj 
A proposta inicial, quando se pensou em trabalhar com a temática da violência urbana em sala de aula, partiu do pressuposto de que a Geografia poderia auxiliar nas discussões sobre o tema, visto que este engloba diversos fatores, tais como: exclusão social, marginalidade, segregação espacial, baixa oferta de emprego, dentre outros. Outro aspecto a destacar, refere-se ao fato de que esta temática (a violência), vem se mostrando bastante recorrente na atualidade, necessitando de maiores reflexões.

A importância de se trabalhar com esta temática em sala de aula também foi evidenciada por Alves e Cardoso (2008, p. 220), em pesquisa desenvolvida junto a alunos do Ensino Médio do Rio Grande do Sul, quando os autores expuseram que:

O tema da violência urbana no Brasil foi proposto porque é de relevante importância trata-lo nas aulas de Geografia, pois ela pode nos auxiliar a entender o atual modelo de urbanização das cidades brasileiras e porque todos podem ser atingidos pela violência.

Ressalta-se que, primeiramente, faz-se necessária uma apresentação da temática proposta com os alunos, sendo evidenciados os diversos tipos de violência que podem ser encontrados, bem como as possíveis causas e medidas mitigadoras, para, posteriormente, apresentar aos alunos o material o qual deverá ser procedida uma análise crítico-reflexiva, podendo esta ser desenvolvida em grupo como forma de buscar a sociabilidade dos alunos. A presente proposta tem a seguinte finalidade:

1. Identificar notícias que envolvessem a temática da violência urbana nos jornais;

2. Discutir sobre qual tipo de violência a notícia se reportava;

3. Refletir sobre as possíveis causas, bem como apontar medidas para solucionálas;

4. Correlacionar, com base nas discussões iniciais, as informações adquiridas na matéria jornalística com os conteúdos ministrados em sala de aula, bem como com o espaço vivido de cada aluno, sendo esta análise realizada de forma individual;

5. Problematizar a análise e correlação solicitada no item acima, devendo esta ser apresentada a turma, por meio de algum tipo de linguagem e/ou representação (redação, poesia, desenhos, quadrinhos, etc.), para posterior socialização;

6. Solicitar aos alunos que discorram sobre a seguinte questão: "Qual seria a relação da educação com a ampliação da violência?".

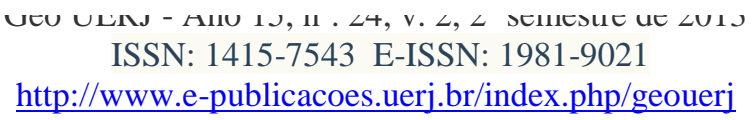




\section{Levando o Cinema para sala de aula: filmes e documentários}

O mundo caminha para a era do domínio de novas tecnologias, novas mídias surgem a cada dia, e sob este contexto o ensino deve também sofrer avanços, adaptar-se as novas linguagens e formas de conhecimento, assim como se tornar mais atraente, dinâmico e que facilite o processo da aprendizagem dos educandos, sob este aspecto, novas mídias educacionais ganham destaques, ou ainda mídias seculares ganham nova importância educacional, entre as quais está o cinema, que pode ser um poderoso instrumento de apoio magistério (ANACLETO et. al., 2007, p.22).

De acordo com Napolitano (2010), o cinema pode ser considerado uma "nova" linguagem centenária, pois apesar de haver completado 100 anos em 1995 a escola o descobriu tardiamente. O que não significa que o cinema não tenha sido pensado, desde os seus primórdios, como elemento educativo, sobretudo em relação às massas trabalhadoras.

Sobre a utilização da linguagem cinematográfica em sala de aula, Miranda e Coppola (2005) destacam que as mídias podem ser consideradas excelentes ferramentas de potencialização da educação. Este recurso extrapola o campo da educação formal em virtude dos arranjos fílmicos funcionarem intrínsecos aos arranjos didáticos, levando o educando a concentrar-se na história humana e aprender a olhar o mundo com outros olhos.

A importância didático-pedagógica do cinema também é ressaltada na obra de Napolitano (2010, p. 11), quando o autor argumenta que: "trabalhar com o cinema em sala de aula é ajudar a escola a reencontrar a cultura ao mesmo tempo cotidiana e elevada, pois o cinema é o campo no qual a estética, o lazer, a ideologia e os valores sociais mais amplos são sintetizados numa mesma obra de arte".

Ainda de acordo com o autor supracitado, é imprescindível que o professor, ao pensar em trabalhar com o cinema em sala de aula, faça algumas perguntas, a saber:

1. Qual o uso possível deste filme?

2. A que faixa etária escolar ele é mais adequado?

3. Como vou abordar o filme dentro da minha disciplina ou num trabalho interdisciplinar?

4. Qual a cultura cinematográfica dos meus alunos?

Geo UERJ - Ano 15, nº. 24, v. 2, $2^{\circ}$ semestre de 2013

ISSN: 1415-7543 E-ISSN: 1981-9021

http://www.e-publicacoes.uerj.br/index.php/geouerj 
Diante do exposto, pode-se inferir que os recursos audiovisuais podem favorecer o processo educativo de maneira significativa, contribuindo desta forma com a formação integral do aluno, como afirma Carneiro (1999, p. 10):

\begin{abstract}
As escolas devem incentivar que se use o vídeo como função expressiva dos alunos, complementando o processo ensino-aprendizagem da linguagem audiovisual e como exercício intelectual e de cidadania necessária em sociedade que fazem o uso intensivo dos meios de comunicação, a fim de que sejam utilizados crítica e criativamente.
\end{abstract}

Apesar de comungarmos com a colocação de Tornero (1994), quando o autor afirma acreditar que os recursos midiáticos viabilizam, aos sujeitos envolvidos, uma leitura crítica de tudo que os rodeiam. Faz-se oportuno ressaltar que um dos grandes equívocos cometidos em sala de aula é quando da utilização desses recursos, neste caso, o filme, com a justificativa de que este irá "ilustrar" e "motivar" os alunos, como ressaltado por Napolitano (2010), quando o desinteresse escolar está alicerçado em bases muito mais complexas.

No que se refere à utilização deste recurso nas aulas de Geografia, Pontuschka (2009), informa que a linguagem do cinema vem sendo cada vez mais usada nas aulas da referida disciplina. Enquanto alguns professores empregam adequadamente essa linguagem, outros ainda apresentam dificuldades de usá-la como recurso didático sem descaracterizar ou esquecer a arte cinematográfica.

A referida autora complementa suas colocações, no que se refere à importância do citado recurso, ressaltando que para os Geógrafos e professores de Geografia, o filme tem importância devido ao fato de este poder servir de mediação para o desenvolvimento das noções de tempo e de espaço na abordagem dos problemas sociais, econômicos e políticos.

Jorge Luiz Barbosa diz acreditar que: “o diálogo da Geografia com cinema é um vir-a-ser, capaz de contribuir para superar a nossa condição de meros objetos das representações. E assim fazer a nossas aulas lugares de invenção de novas e mais generosas utopias” (BARBOSA, 1999, p. 131 apud PONTUSCHKA, 2009).

Assim sendo, observa-se que o filme pode provocar rica discussão entre professores e alunos e ensejar interessante produção didática com base nas reflexões desenvolvidas, em sala de aula, principalmente quando este vem a discutir assuntos relacionados à cotidianidade dos discentes. Podendo, a escolha deste recurso, conforme 
apontado por Napolitano (2010), partir de uma seleção realizada pelo professor juntamente com os alunos, estando os filmes compatíveis com a programação da disciplina escolar.

\section{- Proposta metodológica: discutindo as questões ambientais nas aulas de Geografia} por meio da linguagem cinematográfica

As questões ambientais permeiam as discussões atuais, passando esta a ser a grande preocupação de diversos seguimentos da sociedade, instituições de ensino, governos e empresários. Tais discussões ganharam grande repercussão midiática, o que resultou na utilização desta temática em diversas produções cinematográficas, como exemplos mais atuais, podem ser citados os filmes: Home - o mundo é a nossa casa; Mudanças do clima, mudanças de vida; Avatar; Refugiados do Clima; Saneamento Básico; A carne é Fraca, dentre outros, sendo os dois últimos, produções nacionais.

A presente proposta poderá vir a ser aplicada quando da abordagem de conteúdos relacionados com o sistema econômico capitalista, problemas urbanos e impactos ambientais decorrentes do processo de uso e apropriação dos recursos naturais, estando esta sugestão também presente na obra de Napolitano (2010), sendo esta proposta reformulada para o presente artigo, não comprometendo os objetivos pensados inicialmente pelo autor acima relacionado.

Título do Filme: Ilha das Flores

Direção: Jorge Furtado

Brasil: Sagres, 1988

Área principal: ética/meio ambiente (também áreas de Química, Biologia, e Física)

Cuidados: linguagem sofisticada

Apesar de o filme ser do final da década de 1980, este é bastante atual e sugerido em alguns livros didáticos como complementação e/ou ilustração dos conteúdos abordados, visto que aborda a problemática dos resíduos sólidos urbanos, que vem se configurando, nas últimas décadas, como um dos grandes problemas ambientais urbanos.

Ilha das Flores é um curta metragem brasileiro, que consegue, em cerca de quinze minutos, discutir problemas socioeconômicos e socioambientais. Fazendo uso das 
palavras de Napolitano (2010), o filme se constrói por meio de linguagem ágil e didática, fazendo-se necessário apenas uma atenção maior para com o vocabulário utilizado, que por ser um pouco rebuscado, pode dificultar a compreensão dos alunos, principalmente para os de baixa faixa etária.

O filme conta a estória de um tomate: plantado, colhido, vendido a um supermercado, comprado por uma dona-de-casa, rejeitado na hora de fazer um molho para o almoço, jogado no lixo, levado para a Ilha das Flores, rejeitado pelos porcos, e finalmente, encontrado por uma criança com fome.

Dessa forma, algumas propostas poderiam ser elaboradas para reflexão com os alunos em sala de aula, tais como:

1. Discutir, através de um acompanhamento da trajetória de um simples tomate, desde a plantação até ser jogado fora, o sistema econômico capitalista, enfocando o processo de geração de riqueza e as desigualdades sociais que surgem no meio do caminho;

2. Refletir sobre o que é desenvolvimento e qual seria o modelo de desenvolvimento ideal no ponto de vista dos alunos;

3. Analisar os danos ambientais decorrentes do desenvolvimento econômico vigente, a exemplo da crescente geração dos resíduos sólidos urbanos e os seus impactos nos centros urbanos;

4. Solicitar que os alunos pesquisem, in loco, qual a situação dos resíduos nos seus municípios, se existem pessoas vivendo nas mesmas condições das apresentadas no filme, e qual solução eles poderiam propor;

5. Com base na pesquisa de campo, organizar um grande mural, com exposição fotográfica dos problemas ambientais encontrados pelos alunos em sua escola, sua rua, seu bairro e sua cidade;

6. Por fim, debater com os alunos, tomando por base a frase final do filme "a diferença entre os seres humanos sem dinheiro e os porcos do dono é que os primeiros têm liberdade. Liberdade: essa palavra que o sonho humano alimenta e que não há ninguém que explique e ninguém que não entenda". Após o debate, solicitar uma produção textual, na qual os alunos deverão expressar as suas considerações sobre a atividade desenvolvida.

\section{CONSIDERAÇÕES FINAIS}

Geo UERJ - Ano 15, nº 24, v. 2, $2^{\circ}$ semestre de 2013 ISSN: 1415-7543 E-ISSN: 1981-9021

http://www.e-publicacoes.uerj.br/index.php/geouerj 
Diante das informações apresentadas, observou-se que o perfil do professor interfere no processo de ensino-aprendizagem; que além de um transmissor de conteúdos ele deve ser um estimulador da autorreflexão, levando os alunos a analisarem sua origem através de pensamentos práticos e discursivos, buscando levar a discussão teórica para a realidade local. Desse modo, a introdução de recursos midiáticos em sala de aula possibilitará uma maior interação dos alunos, propiciando o desenvolvimento de novos conhecimentos, assim como uma contextualização e significação dos conceitos apreendidos.

Ressalta-se, que a importância da renovação da Geografia Escolar, reside no fato de esta ciência ser uma importante fonte para desenvolvimento da reflexão, criticidade e criatividade do aluno, de modo a desenvolver neste o verdadeiro senso de cidadania, como forma de possibilitar a formação de alunos que sejam participativos, efetivamente, no processo de transformação, decisão e escolha, não só no meio social em que vive, mas do mundo do qual faz parte.

Apesar de as novas tecnologias (TVs, DVs, Datashow, Computadores, Aparelhos de som, dentre outros) ainda não se fazerem presentes na totalidade das escolas públicas brasileiras, estas unidades de ensino estão a cada dia se renovando, do ponto de vista técnico, cabe ao professor saber manusear tais equipamentos e adequá-los pedagogicamente em suas aulas.

Outrossim, registra-se que a indisponibilidade de tais equipamentos não deve justificar a continuidade e perpetuação de uma Geografia arcaica, pautada em uma metodologia de ensino tradicional, marcada, principalmente, pela não reflexão crítica dos alunos, haja vista, conforme explicitado ao longo desta comunicação, que muitos dos recursos midiáticos aqui exemplificados fazem parte do cotidiano de ambos, aluno e professor, cabendo apenas um novo olhar e uma boa proposta metodológica para que estes possam vir a ser utilizado em sala de aula.

\section{REFERÊNCIAS}

ALVES, M. S. e CARDOSO, E. S. Geografia e a mídia na sala de aula. Disponível em:

<http://cascavel.ufsm.br/revistageografia/index.php/revistageografia/article/viewFile/53 /29>. Acesso em: 20 de abril de 2012.

ANACLETO, A. et. al. Cinema e Home Vídeo Entertaintnment: o mercado da magia e a magia do mercado. Np. 2007. 
AUGUSTO, A. Jornal na sala de aula: leitura e assunto novo todo dia. In: Revista Nova Escola. Publicado em Setembro de 2004. Disponível em: $<$ http://revistaescola.abril.com.br/lingua-portuguesa/pratica-pedagogica/jornal-salaaula-423555.shtml> . Acesso em: 20 de abril de 2012.

BRASIL, Presidência da República. Parâmetros Curriculares Nacionais: História e Geografia - PCN's. Ministério da educação. Secretaria de Educação Fundamental. 3 ed. Brasília, 2001. 166p.

CALLAI, H. C. Projetos interdisciplinares e a formação do professor em serviço. In: PONTUSCHKA, N. N. e OLIVEIRA, A. O. (Orgs.). Geografia em perspectiva. São Paulo: Contexto, 2002. p. 255-259.

CALLAI, H. C. Estudar o lugar para compreender o mundo. In: CASTROGIOVANNI, A. (Org). Ensino de Geografia: práticas e textualizações no cotidiano. Porto Alegre: Mediação, 2003.

CARNEIRO, V. L. Q. Castelo Rá-tim-bum: O educativo como entretenimento. São Paulo. Ed. Annablume. 1999.

CASTELLAR, S. Ensino de Geografia. São Paulo: Cengage Learning, 2010.

CAVALCANTI, L. de S. Geografia, escola e construção do conhecimento. 17ed. Campinas: Papirus, 2010.

FARIAS, M. A. O jornal na sala de aula. 13 ed. São Paulo: Contexto, 2004.

FREIRE, P. Pedagogia da Autonomia: saberes necessários à prática educativa. 39 ed. São Paulo: Paz e Terra, 2009.

GAIA, R. Notícias na Escola: possibilidades de leituras críticas. In: Anais... do XXV Congresso Anual em Ciência da Comunicação, Salvador/BA, 2002. Disponível em: $<$ http://reposcom.portcom.intercom.org.br/dspace/bitstream/1904/18913/1/2002_NP11

GAIA.pdf>. Acesso em: 25 de junho de 2012.

GUIMARÃES, I. V. Ensino de geografia, professores e a relação escola/tv. In: Boletim Paulista de Geografia. n.79. São Paulo: AGB, 2003.

KAERCHER, N. A. O gato comeu a geografia crítica? alguns obstáculos a superar no ensino-aprendizagem de Geografia. In: PONTUSCHKA, N.N, OLIVEIRA, O. (orgs). Geografia em Perspectiva. São Paulo: Contexto, 2002. p. 221 - 231.

KAERCHER, N. A. Geografizando o jornal e outros cotidianos: práticas em Geografia para além do livro didático. In: CASTROGIOVANNI, A. C. (org.). Ensino de Geografia: práticas e textualizações no cotidiano. Porto Alegre: Mediação, 2003. 
KATUTA, A. M. O ensino da Geografia e as figurações espaciais. In: ROMANOWISKI, J. P.; MARTINS, P. L. O. e JUNQUEIRA, S. R. A. (Orgs.). Conhecimento local e conhecimento universal: práticas sociais, aulas, saberes e políticas. V. 4. Curitiba: Champagnat, 2004, p. 113-130.

KOZEL, S. T. Geografia, Representação e Ensino: um olhar sobre a dimensão cultural. In: Anais... do I Colóquio Nacional do Núcleo de Estudos em Espaço e Representação, 2006, Curitiba. Editora da UFPR, 2006. p. 45-58.

NAPOLITANO, M. Como usar o cinema na sala de aula. 4 ed. São Paulo: Contexto, 2010.

MELO, E. C. L. de, et al. Geografia. Disponível em : < http://www.vitoria.es.gov.br/arquivos/20100218_ens_fund_dir_geografia.pdf>. Acesso em: 20 de março de 2009.

MIRANDA, C. E. A. e COPPOLA, D. G. F. A educação pelo cinema. In: Revista Educação e Cinema, Unicamp/SP, p.02, 2005. Disponível em: $<$ http://setimaartefaeufmg.files.wordpress.com/2011/12/miranda-cea-educcinema1.pdf >. Acesso em: 10 de fevereiro de 2009.

OLIVEIRA, A. U. Situação e tendências da geografia. In: OLIVEIRA, A. U. (Org.). Para onde vai o ensino de geografia? 4. ed. São Paulo: Contexto, 1994. p. 24-29.

OLIVEIRA, H. C. M. de, et. al. A música como um recurso alternativo nas práticas educativas em Geografia: algumas reflexões. In: Revista Caminhos de Geografia. Uberlândia/MG, ano 8, n. 15, jun/2005, p. 73-81.

PAVINI, C. (org.). Jornal: (in)formação e ação. 2 ed. Campina/SP: Papirus, 2002.

PINHEIRO, E. A. et. al. O nordeste brasileiro nas músicas de Luiz Gonzaga. Caderno de Geografia, Belo Horizonte, v.14, n. 23, 2º sem/2004, p. 103-111.

PONTUSCHKA, N. N. et al. Para ensinar e aprender Geografia. 3 ed. São Paulo: Cortez, 2009.

PRADO, M. E. B. B. Integração de mídias e a reconstrução da prática pedagógica. Publicado em 21 de fevereiro de 2009. Disponível em: <http://midiasnaeducacaojoanirse.blogspot.com.br/2009/02/integracao-de-tecnologias-com-as-midias.html >.

Acesso em: 20 de junho de 2012.

RESENDE, M. S. A geografia do aluno trabalhador. São Paulo: Loyola, 1986.

SANTOS, M. F. P. dos e CALLAI, H. C. Tecnologias de informação no ensino da geografia. In: Anais... do $10^{\circ}$ Encontro Nacional de Prática de Ensino em Geografia ENPEG. De 30 de agosto a 02 de outubro de 2009 em Porto Alegre. Disponível em: <http://www.agb.org.br/XENPEG/artigos/Poster/P\%20(38).pdf >. Acesso em: $20 \mathrm{de}$ abril de 2012. 
TORNERO, J. M. P. El desafio educativo de la televisión. In: Associação Nacional de Pós-Graduação e Pesquisa em Educação - ANPED, 1994. Disponível em: < http://www.anped.org.br>. Acesso em: 27 de novembro de 2009.

VESENTINI, J. W. Geografia crítica e ensino. In: OLIVEIRA, A. U. (Org.). Para onde vai o ensino de geografia? 4. ed. São Paulo: Contexto, 1994. p. 30-38.

VIEIRA, C. E. e SÁ, M. G. Recursos didáticos: do quadro-negro ao projetor, o que muda? In: PASSINI, E. Y. Prática de Ensino de Geografia e Estágio Supervisionado. São Paulo: Contexto, 2007.

Artigo recebido para publicação em abril de 2013.

Artigo aceito para publicação em junho de 2013. 